М. Й. Заполовський, М. В. Мезенцев

Національний технічний університет «Харківський політехнічний інститут», Харків, Україна

\title{
СИНТЕЗ КЕРУВАНЬ ДИЗЕЛЬ-ПОЇЗДА З ЕЛЕКТРОПРИВОДОМ ЗМІННОГО СТРУМУ
}

\begin{abstract}
Анотація. Завдання синтезу системи керування тяговим електроприводом змінного струму є складовою частиною загального завдання створення оптимальної системи керування транспортними засобами, що забезпечує виконання графіка руху у відповідності заданому критерію якості. Метою даної роботи $є$ розроблення математичних моделей для синтезу системи керування електроприводу змінного струму з використанням алгоритму векторного управління, синтез управлінь та проведення досліджень їх моделей, отримання якісних характеристик роботи системи керування в процесі моделювання з використанням пакету MATLAB. Розглянуті питання синтезу систем керування тяговим електроприводом змінного струму дизель-поїзда та їх дослідження за допомогою математичних моделей, які реалізовані в пакеті MATLAB. Проведено огляд літературних джерел на задану тематику та аналіз існуючих підходів до розв'язання задач синтезу систем керування у даній галузі, зокрема систем керування 3 використанням алгоритмів векторного управління. Виконано синтез управлінь, побудовані математичні моделі досліджуваних об'єктів керування, проведене моделювання їхнього функціонування. Отримані аналітичні співвідношення, які можуть бути використані для розробки структури САР електроприводу дизель-поїзда і розрахунку їі параметрів при задані критерію якості з урахуванням певного завантаження дизель-поїзда. Синтезовані закони управління забезпечують стійкий розгін дизель-поїзда в різних точках тягової характеристики і при цьому виконуються вимоги щодо точності приведення об’ єкта керування в задану точку фазового простору і якості перехідних процесів.
\end{abstract}

Ключов і слов а: синтез систем керування, електропривод змінного струму, дизель-поїзд, алгоритми векторного управління, аналітичні співвідношення, математична модель, закони управління.

\section{Вступ}

Завдання синтезу системи керування тяговим електроприводом змінного струму є складовою частиною загального завдання створення оптимальної системи керування транспортними засобами, що забезпечує виконання графіка руху у відповідності заданому критерію якості. Останніми роками вирішення цих завдань пропонується виконувати з використанням сучасних комп'ютерних технологій, в основу яких покладено методи математичного моделювання, аналізу і синтезу складних технічних систем. Тому розробка оптимальних систем керування та моделей для їх дослідження $є$ актуальною задачею.

Постановка задачі і аналіз відомих публікацій. На сьогоднішній день наряду з частотним способом керування електроприводом змінного струму все більшої уваги приділяється розробкам систем керування на основі алгоритмів векторного управління [1-9]. Ці алгоритми активно впроваджується у високоякісних електроприводах трифазного струму. В алгоритмах керування закладена ідея орієнтування потоку асинхронного двигуна [2, 4, 8, 9]. Напруги статора (керуючі впливи) системи рівнянь (математичної моделі) трифазного асинхронного двигуна як в рухомій, так і нерухомій системі координат визначаються по рівняннях векторного управління.

Рішення задачі розроблення оптимальної системи керування електроприводом змінного струму в першу чергу пов'язане зі створенням нелінійних математичних моделей з врахуванням особливостей використання того чи іншого методу синтезу управлінь, критеріїв оцінки якості функціонування системи керування, проведенням комплексних досліджень динаміки електромеханічної системи електроприводу. Для рішення завдань оптимального керування присвячено значне число публікацій [6], де для синтезу використовується математичне моделювання, сучасні методи теорії автоматичного керування та оптимізації, комп'ютерні технології. В [6] пропонується ряд методів синтезу управлінь та математичні моделі електроприводу змінного струму, які можуть бути використані при розробці систем управління з урахуванням вибраного критерію оптимальності. Як правило, задовільний результат отримується при синтезі оптимальних систем керування для об'єктів, які описуються системою диференційних рівнянь не вище третього порядку. Для систем вищих порядків, а також нелінійних моделей, можливо використовувати комбінований метод знаходження управлінь. Він зводиться до наступного [9]. На першому етапі з використанням спрощеної моделі електроприводу знаходиться загальний вид управлінь. На другому - задаються закони можливих управлінь та в процесі дослідження уточняються їх види та параметри системи керування за допомогою повної математичної моделі.

Метою роботи $\epsilon$ розроблення математичних моделей для синтезу системи керування електроприводу змінного струму з використанням алгоритму векторного управління, синтез управлінь та проведення досліджень їх моделей, отримання якісних характеристик роботи системи керування в процесі моделювання з використанням пакету MATLAB.

\section{Основна частина}

Вихідними змінними для даного об'єкту управління $є$ швидкість руху $\mathrm{V}$ і пройдений шлях $\mathrm{S}$. За відсутності боксування швидкість руху пропорційна кутовій електричній швидкості обертання ротора двигуна $\omega$. Рівняння руху має вигляд [1]:

$$
\frac{d \omega}{d t}=K_{1}\left(M_{t}-M_{c}\right),
$$


де $M_{t}$ - тяговий момент дизель-поїзда; $K_{1}=p / J_{t}$; $J_{t}$ - момент інерції дизель-поїзда; $M_{c}-$ момент опору руху, який згідно правил тягових розрахунків, знаходиться згідно виразу:

При номінальному завантажені :

$$
M_{c}=1299(1.1+0.012 * 0.1545 \omega)(\text { Нм }),
$$

або

$$
M_{c}=1299(1.1+0.012 * 0.1545 \omega)(H м) .
$$

За умови, що тяговий момент дизель-поїзда здійснюють чотири двигуни, то рівняння руху матиме вигляд:

$$
\frac{d \omega}{d t}=K_{1}\left(4 M_{d} * i-M_{c}\right)
$$

де $M_{d}$ - електромагнітний момент двигуна; i - передавальне число редуктора $(i=3.69)$.

3 урахуванням рівняння (2), отримаємо:

$$
\begin{aligned}
\frac{d \omega}{d t} & =K_{1}\left(K_{2} M_{d}-1429-2.41 \omega\right)= \\
& =K_{1}\left(K_{2} M_{d}-K_{3}-K_{4} \omega\right),
\end{aligned}
$$

де $K_{2}=14.76 ; K_{3}=1429 ; K_{4}=2.41$.

або

$$
\frac{d \omega}{d t}=K_{5} M_{d}-K_{6} \omega-K_{7},
$$

де $K_{5}=K_{1} K_{2}=0.000915 ; K_{6}=K_{1} K_{4}=0.00015$; $K_{7}=K_{1} K_{3}=0.089$.

Можемо записати:

$$
\frac{d X_{1}}{d t}=K_{5} M_{d}-K_{6} X_{1}-K_{7}
$$

В результаті отримали диференційне рівняння першого прядку, яке описує динаміку руху дизельпоїзда при номінальному завантаженні. В якості управління виступає електромагнітний момент тягового двигуна $M_{d}$. Для його визначення використаємо модель тягового двигуна у вигляді системи диференційних рівнянь, де для формування напруги живлення та їі частоти використовується алгоритм векторного управління.

Згідно $[4,9]$, за умови, якщо швидкість обертання координат $\omega_{k}$ співпадає із швидкістю вектора потоку ротора $\omega_{\psi}\left(\omega_{k}=\omega_{\psi}\right)$, то вектор потокозчеплення ротора $\Psi_{r}$ відображається на вісі 1 своїм модулем $\Psi_{r m}$, а його проекція на вісь 2 дорівнює нулю і рівняння, що описують динаміку електромагнітних процесів тягового двигуна, приймають вигляд $[1,2]$ :

$$
\begin{gathered}
U_{s 1}=\frac{d \Psi_{s 1}}{d t}-\Psi_{s 2} \omega_{\Psi}+R_{S} I_{s 1} ; \\
U_{s 2}=\frac{d \Psi_{s 2}}{d t}+\Psi_{s 1} \omega_{\Psi}+R_{S} I_{s 2} ; \\
0=\frac{d \Psi_{r m}}{d t}+R_{R} I_{r 1} ; \\
0=\left(\omega_{\Psi}-p \omega\right) \Psi_{r m}+R_{R} I_{r 2} ;
\end{gathered}
$$

$$
M_{d}=\frac{m p K_{r}}{2} \Psi_{r m} I_{s 2}
$$

де $\Psi_{r m}$ - модуль вектора потоку ротора; $I_{s 1}, I_{s 2}$, $I_{r 1}, I_{r 2}$ - відповідно проекції на вісі координат струмів статора і ротора; $R_{S}, R_{R}$ - відповідно активні опори обмоток статора і ротора ТАД; $\mathrm{m}$ - число фаз; р - число пар полюсів; $K_{r}$ - коефіцієнт зв'язку ротора; $\omega-$ швидкість обертання ротора; $\omega_{s}-$ швидкість вектора напруги статора; $\omega_{\psi}-$ швидкістю вектора потоку ротора.

Використовуючи рівняння зв'язку $[2,3]$

$$
\Psi_{r}=I_{r} L_{r}+I_{s} L_{m} ; \Psi_{s}=I_{s} L_{s}+I_{r} L_{m},
$$

отримаємо:

$$
\begin{gathered}
U_{s 1}=\frac{d I_{s 1}}{d t} L_{s}{ }^{\prime}+K_{r} \frac{d \Psi_{r 1}}{d t}-I_{s 2} L_{s}{ }^{\prime} \omega_{\Psi}+R_{s} I_{s 1} \\
U_{s 2}=\frac{d I_{s 2}}{d t} L_{s}{ }^{\prime}+I_{s 1} L_{s}{ }^{\prime} \omega_{\Psi}+K_{r} \Psi_{r m}+R_{s} I_{s 2} ; \\
0=\frac{d \Psi_{r m}}{d t}+\frac{R_{r}}{L_{r}} \Psi_{r m}-I_{s 1} K_{r} R_{r} ; \\
0=\beta \Psi_{r m}-I_{s 2} K_{r} R_{r} ; \\
M_{d}=\left(m p K_{r} / 2\right) \cdot \Psi_{r m} I_{s 2}
\end{gathered}
$$

де $L_{s}{ }^{\prime}=L_{s}-L_{m}^{2} / L_{r}, K_{r}=L_{m} / L_{r}$.

Використовуючи рівняння (11) i (12) і рівняння зв'язку для системи управління 3 регулюванням напруги живлення, знаходимо співвідношення, за допомогою яких визначаються проекції напруги живлення ТАД по кожній із вісей при відомій її частоті.

$$
\begin{gathered}
U_{s 1}=R_{s} I_{s 1}-I_{s 2} L_{s}{ }^{\prime} \omega_{\Psi} ; \\
U_{s 2}=R_{s} I_{s 2}+\omega_{\Psi} \Psi_{r m}\left(L_{s}{ }^{\prime} / L_{m}+K_{r}\right) .
\end{gathered}
$$

Момент тягового двигуна $M_{d}$ знаходиться згідно рівняння (15) по відповідним значенням потокозчеплення $\Psi_{r m}$ і струму $I_{s 2}$. Для визначення потокозчеплення $\Psi_{r m}$ використаємо диференційне рівняння (13). Тяговий момент, як управління в рівнянні (5), визначається фазовою змінною $\Psi_{r m}$ і проекцією вектора струму статора - струмом $I_{s 2}$.

Змінна $\Psi_{r m}$, згідно диференційного рівняння (13), визначається струмом $I_{s 1}$. В результаті, в якості управлінь, можемо вибрати проекції вектора струму статора - струми $I_{s 1}$ і $I_{s 2}$.

3 урахуванням динамічних процесів для визначення проекції потоку ротора $\Psi_{r m}$ використаємо рівняння (13) у вигляді:

$$
\frac{d \Psi_{r m}}{d t}=-\frac{R_{r}}{L_{r}} \Psi_{r m}+I_{s 1} \frac{L_{m} R_{r}}{L_{r}} .
$$

При заданих параметрах ТАД отримаємо:

$$
\frac{d \Psi_{r m}}{d t}=-0.771 \Psi_{r m}+0.0668 I_{s 1} .
$$


Аналогічно із рівнянням (5) рівняння (19) для оптимізаційної моделі запишемо у вигляді:

$$
\frac{d X_{2}}{d t}=-0.771 X_{2}+0.0668 I_{s 1} .
$$

В результаті, для синтезу управлінь об'єкт дослідження можливо представити математичною моделлю у вигляді системи диференційних рівнянь другого порядку:

$$
\begin{gathered}
\dot{X}_{1}+a_{11} X_{1}-a_{12} X_{2} U_{1}+0.089=0, \\
\dot{X}_{2}+a_{21} X_{2}-a_{22} U_{2}=0 .
\end{gathered}
$$

де $X_{1}, X_{2}, \dot{X}_{1}, \dot{X}_{2}$ - відповідно фазові змінні та їх похідні; $U_{1}, U_{2}$ - управління; $\mathrm{a}_{11}, \mathrm{a}_{12}, \mathrm{a}_{21}, \mathrm{a}_{22}$ - коефіцієнти, які визначаються параметрами системи.

Для системи, яка досліджується:

$$
\begin{gathered}
X_{1}=\omega ; X_{2}=\Psi_{r m} ; \mathrm{a}_{11}=0.00015 ; \mathrm{a}_{12}=0.004 ; \\
\mathrm{a}_{21}=0.771 ; \mathrm{a}_{22}=0.068 ; U_{1}=I_{s 2} ; U_{2}=I_{s 1} ; \mathrm{m}=3 ; \\
\mathrm{p}=3 ; k_{r}=0.982 ; L_{m}=0.0917 \Gamma \mu .
\end{gathered}
$$

Допустимі межі зміни процесів (управлінь) в процесі розгону дизель-поїзда.

Номінальний момент ТАД - 4800 Нм.

Робочий (можливий) діапазон зміни величини ковзання $-\beta=(0 \div 12) 1 /$ сек.

Діапазон зміни потокозчеплення $\Psi_{r m}$ можливо визначити, використовуючи рівняння (14) і (15). Виходячи із них слідує:

$$
\Psi_{r m}^{2}=2 M_{d} R_{r} /(\beta m p) .
$$

Тоді діапазон зміни $\Psi_{r m}=(1.6 \div 16)$ (В).

Робочий діапазон зміни потокозчеплення становить: $\Psi_{r m}=(1.6 \div 16.0)$ В. При цьому струм $I_{s 2}$, а значить і максимальне значення управління $U_{1}$, становить 2444 (А). Діапазон зміни управління $U_{2}$, що відповідає в дійсності струму $I_{s 1}$, можливо визначити за допомогою рівняння (13), розглядаючи його як сталий процес, тобто:

$$
\frac{R_{r}}{L_{r}} \Psi_{r m}-I_{s 1} K_{r} R_{r}=0 \text {, тоді } I_{s 1}=\frac{\Psi_{r m}}{k_{r} L_{r}} \approx 70 \text { (A). }
$$

Оскільки математична модель об'єкта 3 використанням алгоритму векторного управління за певних обмежень може бути представлена системою диференційних рівнянь другого порядку (рівняння (21) - (22)), то для синтезу управлінь пропонується використати один з методів варіаційного числення рішення загальної задачі Лагранжа.

Використовуючи метод варіаційного числення, як рішення загальної задачі Лагранжа, математична модель об'єкту задається у вигляді системи диференційних рівнянь у вигляді:

$$
\dot{X}_{j}-\psi_{j}\left(X_{1}, X_{2}, \ldots, X_{n}, U_{j}\right)=0,
$$

де $X_{j}$ - змінні співвідношення; $U_{j}$ - управління, відомі початкові і кінцеві стани: $X_{j}(0), X_{j}(T)$.
Заданий критерій оптимальності:

$$
J=\int_{t_{0}}^{T} G\left(X_{1}, X_{2}, \ldots, X_{n}, U_{j}\right) d t .
$$

Відомі області допустимих управлінь.

Рівняння об'єкту розглядаються як рівняння зв'язків в загальній задачі Лагранжа варіаційного числення. Критерієм оптимальності є функціонал, що мінімізується.

Якщо на управління і стани ніяких обмежень не накладено, то рішення задачі оптимізації шукається по аналогії з методами варіаційного числення. 3 цією метою складається допоміжний функціонал:

$$
J_{1}=\int_{t_{0}}^{T}\left[G+\sum_{j=1}^{n} \lambda_{j}(t)\left(\dot{X}_{j}-\psi_{j}\right)\right] d t=\int_{t_{0}}^{T} G_{1} d t .
$$

Відносно функцій $U_{j}, X_{j}, \lambda_{j}$ складаються рівняння Ейлера:

$$
\frac{\partial G_{1}}{\partial U_{i}}-\frac{d}{d t} \frac{\partial G_{1}}{\partial \dot{U}_{i}}=0 .
$$

Тут в рівнянні (26) під $U_{i}$ розуміються функції $U_{j}, X_{j}, \lambda_{j}$. В результаті отримаємо систему рівнянь по числу невідомих $U_{j}(t), X_{j}(t), \lambda_{j}(t), j=\overline{1, n}$.

Розглянемо синтез управлінь за допомогою моделі оптимізації відносно енергетичних витрат при розгоні дизель - поїзда за заданий час і виконання граничних умов по швидкості і пройденому шляху.

Функціонал, що мінімізує енергетичні витрати, можливо задати у вигляді:

$$
J=\int_{t_{0}}^{T}\left(U_{1}^{2}+U_{2}^{2}\right) t d t
$$

де $U_{1}, U_{2}$ - управління; $t_{0}, T$ - початковий та кінцевий терміни часу розгону $t$. Тоді нова підінтегральна функція $\mathrm{G}_{1}$ описується співвідношенням:

$$
\begin{aligned}
G_{1}= & \left(U_{1}^{2}+U_{2}^{2}\right) t+\lambda_{2}\left(\dot{X}_{2}+a_{21} X_{2}-a_{22} U_{2}\right)+ \\
& +\lambda_{1}\left(\dot{X}_{1}+a_{11} X_{1}-a_{12} X_{2} U_{1}+0.089\right) .
\end{aligned}
$$

На підставі рівняння Ейлера (26) складемо співвідношення для знаходження рівнянь $U_{1}, U_{2}$ :

$$
\begin{array}{ll}
\text { для } U_{1}: & \frac{\partial G_{1}}{\partial U_{1}}=2 U_{1} t-a_{12} \lambda_{1} X_{2}=0 . \\
\text { для } U_{2}: & \frac{\partial G_{1}}{\partial U_{2}}=2 U_{2} t-a_{22} \lambda_{2}=0 .
\end{array}
$$

Тоді управління $U_{1}, U_{2}$ знаходяться як:

$$
\begin{gathered}
U_{1}=a_{12} \lambda_{1} X_{2} / 2 t ; . \\
U_{2}=a_{22} \lambda_{2} / 2 t .
\end{gathered}
$$

Невідомими $є \lambda_{1}$ та $\lambda_{2}$.

Для визначення $\lambda_{1}$ та $\lambda_{2}, X_{1}$ та $X_{2}$ складемо рівняння Ейлера згідно (26). 


$$
\begin{gathered}
\frac{\partial G}{\partial \lambda_{1}}=\dot{X}_{1}+a_{11} X_{1}-a_{12} X_{2} U_{1}+0.089=0 ; \\
\frac{\partial G}{\partial \lambda_{2}}=\dot{X}_{2}+a_{21} X_{2}-a_{22} U_{2}=0 .
\end{gathered}
$$

В результаті отримали аналогічні співвідношення, що відповідають начальним рівнянням (21), (22) для знаходження невідомих $X_{1}$ i $X_{2}$ та описують динаміку досліджуємого об’єкта управління.

Аналогічно знаходяться рівняння для визначення невідомих $\lambda_{1}$ та $\lambda_{2}$.

$$
\begin{gathered}
\frac{\partial G}{\partial X_{1}}-\frac{d}{d t} \frac{\partial G}{\partial \dot{X}_{1}}=a_{11} \lambda_{1}-\dot{\lambda}_{1}=0 \\
\frac{\partial G}{\partial X_{2}}-\frac{d}{d t} \frac{\partial G}{\partial \dot{X}_{2}}=-a_{12} U_{1} \lambda_{1}+a_{21} \lambda_{2}-\dot{\lambda}_{2}=0
\end{gathered}
$$

Для визначення невідомих $\lambda_{1}$ та $\lambda_{2}$ отримаємо систему диференційних рівнянь:

$$
\begin{gathered}
\dot{\lambda}_{1}-a_{11} \lambda_{1}=0 ; \\
\dot{\lambda}_{2}+\lambda_{1} a_{12} U_{1}-a_{21} \lambda_{2}=0 .
\end{gathered}
$$

В результаті отримали систему диференційноалгебраїчних рівнянь для знаходження $U_{1}$ i $U_{2}$.

Оскільки з однієї сторони система рівнянь нелінійна, а 3 другої знаходження невизначених множників Лагранжа $\lambda_{1}$ i $\lambda_{2}$ потребує для їх знаходження багатократного перебору варіантів, то piшення задачі знаходження управлінь, які б задовольняли критерію оптимізації згідно з виразом (27), можливо шляхом моделювання. Визначимо межі можливих змін управлінь $U_{1}$ і $U_{2}$.

Із (31) і (32) виходить:

$$
\begin{gathered}
\lambda_{1}(t)=\frac{2 U_{1} t}{a_{12} x_{2}}=\frac{2 * 2444 * 60}{0.004 * 1.6}=45825000 ; \\
\lambda_{2}(t)=\frac{2 U_{2} t}{a_{22}}=\frac{2 * 70 * 60}{0.068}=123530 .
\end{gathered}
$$

Знаходження $\lambda_{1}(t)$. Для його знаходження використаємо отримане рівняння (31): $\dot{\lambda}_{1}-a_{11} \lambda_{1}=0$. Його рішення:

$$
\lambda_{1}(t)=C_{1} e^{a_{11} t}
$$

де $C_{1}$ - постійна інтегрування, яка, як правило, знаходиться із начальних умов (початкових і кінцевих станів об’єкту) диференційного рівняння.

Оскільки $\lambda_{1}(t)$ визначає управління $U_{1}(t)$, яке входить в диференційне рівняння руху (21), де начальними умовами $є$ швидкості руху дизель-поїзда (начальна і кінцева), знайдемо значення $C_{1}$. Допустимо, що розгін дизель-поїзда виконується від швидкості $x_{10}=0(1 / c)$ до швидкості $x_{11}=35.0(1 / c)$ (60 км/год) за час $t=60 c$.

Так як сумісно рівняння (21) і (35) - диференційне рівняння другого порядку, то відомі начальні умови дають можливість визначити дві постійних інтегрування, одна 3 яких є $C_{1} .3$ врахуванням рівняння управління (31), рівняння (21) прийме вид:

$$
\dot{X}_{1}+a_{11} X_{1}=\left(a^{2}{ }_{12} X_{2}{ }^{2} \lambda_{1}\right) /(2 t)=f\left(C_{1}, X_{2}, e^{a_{11} t}, t\right) \text {. }
$$

Аналітичне рішення рівняння (40) за певних умов (при постійному потокозчепленні $X_{20}$ ) включає дві складові: рішення однорідного рівняння і вимушеного. Тоді:

$$
X_{1}(t)=C_{2} e^{-a_{11} t}+X_{1 B}\left(f\left(C_{1}, X_{20}, e^{a_{11} t}, t\right)\right) .
$$

В результаті маємо дві невідомі постійні інтегрування $C_{1}$ та $C_{2}$, значення яких можливо знайти по заданих значеннях начальних умов по швидкості руху. Проаналізуємо рівняння (41).

Складова $X_{10}=C_{2} e^{-a_{11} t}$ (рішення однорідного рівняння) взагалі визначає характер зміни фазової координати $X_{1}(t)$. Друга складова - вимушена. При дослідженні можливо розглядати їі зміни, використовуючи типові функції (постійну, часову, експоненційну та інші).

Розглянемо вимушену складову від функції $f\left(C_{1}, X_{20}, e^{a_{11} t}, t\right)$ при конкретних значеннях параметрів об'єкта управління з метою спрощення знаходження постійних інтегрування при рішенні рівняння (40).

$$
C_{1} e^{a_{11} t} \frac{a_{12}^{2} X_{20}^{2}}{2 t}=C_{1} e^{0.00015 t} \frac{a_{12}^{2} X_{20}^{2}}{2 t}=\frac{C_{1} k_{1}}{t}=\frac{k_{2}}{t},
$$

де $k_{1}=a^{2}{ }_{12} X^{2}{ }_{20} / 2, \quad k_{2}=C_{1} k_{1}, t=(1 \div 60)$.

В результаті отримаємо рівняння:

$$
\dot{X}_{1}+a_{11} X_{1}=k_{2} / t \text {. }
$$

Його рішення:

$$
X_{1}(t)=C_{2} e^{-a_{11} t}+\frac{C_{1} a^{2}{ }_{12} X^{2} 20}{2\left(a_{11} t-1\right)} .
$$

Знайдемо постійні інтегрування із системи рівнянь:

$$
\left\{\begin{array}{l}
C_{2}-C_{1} a^{2}{ }_{12} X^{2}{ }_{20} / 2=0 \\
\frac{C_{2}}{e^{a_{11} t_{i}}}-\frac{C_{1} a^{2}{ }_{12} X^{2}}{2\left(a_{11} t_{i}-1\right)}=X_{1 t i} .
\end{array}\right.
$$

В результаті, якщо для кожного конкретного значення $t_{i}$ відомі граничні умови, тобто знаємо значення швидкості $X_{1 t i}$, то можливо знайти значення $C_{1}$ i $C_{2}$ для кожного конкретного значення $X_{1 t i}$. До того ж залежність швидкості від часу носить нелінійний характер. Можливо аналітично знайти тільки приблизні значення постійних інтегрування $C_{1}$ i $C_{2}$ з подальшим уточненням їх за допомогою моделювання. Знаходження постійних інтегрування $C_{1}$ i $C_{2}$ шляхом рішення системи (44) пропонується у вигляді співвідношень:

$$
C_{1}=2 C_{2} /\left(a_{12}^{2} X_{20}^{2}\right) \text {, }
$$




$$
C_{2}=C_{21}\left(1+k_{3} x_{1}\right),
$$

де $C_{21}, k_{3}$ - відповідно константа і коефіцієнт пропорціональності, які розраховуються згідно системи рівнянь (44) і в подальшому уточнюються на моделі. Начальні (стартові) значення $C_{21}, k_{3}$ можливо розрахувати при значеннях швидкостей в начальний $\mathrm{i}$ кінцевий моменти розгону дизель-поїзда.

Так в процесі дослідження (табл. 1,2$)$ за умови забезпечення мінімізації функціоналу (27) при розгоні дизель-поїзда значення коефіцієнтів: $C_{21}=170$, $k_{3}=0.019$. Постійна інтегрування $C_{2}$ не залежить від величини потокозчеплення $X_{2}$, а визначається тільки начальними умовами і часом руху.

Функція $\lambda_{1}(t)$ визначається як:

$$
\lambda_{1}(t)=C_{1} e^{a_{11} t}=\frac{2 C_{2} e^{a_{11} t}}{a_{12}{ }^{2} x_{2}{ }^{2}}=\frac{C_{21}\left(1+k_{3} x_{1}\right)}{a_{12}{ }^{2} x_{2}{ }^{2}} e^{a_{11} t}
$$

В результаті управління $U_{1}(t)$ можливо формувати згідно виразу:

$$
U_{1}(t)=\frac{C_{2} e^{a_{11} t}}{a_{12} x_{2} t}=\frac{C_{21}\left(1+k_{3} x_{1}\right)}{a_{12} x_{2} t} e^{a_{11} t} .
$$

Постійна інтегрування $C_{2}$ визначає складову рішення однорідного рівняння руху об'єкта управління: $X_{10}=C_{2} e^{-a_{11} t}=C_{21}\left(1+k_{3} x_{1}\right) e^{-0.00015 t}$. Постійна інтегрування $C_{1}$ визначає характер зміни $\lambda_{1}$ $\left(\lambda_{1}=C_{1} e^{a_{11} t}\right)$, а значить і управління $U_{1}(t)$.

3 отриманого співвідношення (48) виходить, що управління $U_{1}(t)$ прямо пропорційне швидкості руху дизель-поїзда і зворотно пропорційне потокозчепленню $X_{2}$ та часу руху $t$ для певної завантаженості дизель-поїзда (визначається коефіцієнтом $\left.a_{11}\right)$. Управління $U_{2}(t)$ знаходиться згідно формули (32), де $\lambda_{2}$ множник Лагранжа.

Диференційне рівняння для визначення $\lambda_{2}$, яке отримано на основі рівнянь Ейлера (36), має вид:

$$
\dot{\lambda}_{2}-a_{21} \lambda_{2}+2 C_{2}^{2} e^{2 a_{11} t} /\left(a_{12}{ }^{2} X_{20}{ }^{3} t\right)=0 .
$$

Якщо прийняти до уваги, що $e^{2 a_{11} t} \approx 1$ за час розгону дизель-поїзда, то рівняння (49) може бути представлено у вигляді:

де

$$
\begin{gathered}
\dot{\lambda}_{2}-a_{21} \lambda_{2}=-k_{3} / t, \\
k_{3}=2 C_{2}^{2} /\left(a_{12}{ }^{2} X_{20}{ }^{3}\right) .
\end{gathered}
$$

Рішення рівняння (50) знайдемо у вигляді:

$$
\lambda_{2}=C_{3} e^{a_{21} t}+2 C_{2}^{2} /\left(a_{12}^{2} X_{20}^{3}\left(a_{21} t+1\right)\right),
$$

де $C_{3}$ - постійна, яка потребує визначення.

Управління $U_{2}$, буде визначатись рівнянням:

$$
U_{2}(t)=\frac{a_{22}}{2 t}\left(C_{3} e^{a_{21} t}+\frac{2 C_{2}^{2}}{a_{12}{ }^{2} X_{20}{ }^{3}\left(a_{21} t+1\right)}\right) \text {. }
$$

Постійну інтегрування $C_{3}$ можемо знайти за умови розрахункових значень діапазону управління $U_{2}(t)\left(U_{20}=(0 \div 70) A\right)$. Тоді при $t=1$ :

$U_{2}(t)=\frac{a_{22}}{2 t} k_{4} C ; k_{4} C_{3}=\frac{140}{0.068} e^{-a_{21} t}=2058.8 e^{-a_{21} t}$.

Управління $U_{2}(t)$ можливо представити як:

$$
U_{2}(t)=205.9 /\left(k_{4} t+1\right),
$$

де $k_{4}$ - коефіцієнт, який визначається в процесі моделювання. Так, в процесі дослідження за умови забезпечення мінімізації функціоналу (27) при розгоні дизель-поїзда $k_{4}=0.1$.

Перевірка законів управління досліджувалась на основі математичної моделі, реалізованої в середовищі MATLAB. Вона складається із наступних моделей: формування управлінь відповідно до синтезованих законів (співвідношень (48) та (52)), моделі електромеханічної частини електроприводу дизель-поїзда $з$ тяговими двигунами змінного струму ТАД у вигляді системи диференційних рівнянь п'ятого порядку в рухомій системі координат d-q [3, 6], блока моделі формування напруг $U_{s 1}$ i $U_{s 2}$ згідно рівнянь (16) і (17) і на їх основі напруги живлення $U_{x 1}$ моделі ТАД в рухомій системі координат, формування швидкості руху дизель-поїзда рівняння (4) і (15), блоків моделей формування абсолютних значень потокозчеплення $\Psi_{r m}$ і управлінь $U_{1}(t)$ та $U_{2}(t)$, моделей формування споживчої потужності тяговим електроприводом, числових значень функціонала згідно рівняння (27). Момент опору руху $M_{c}$, згідно правил тягових розрахунків, задавався рівнянням (2).

В процесі досліджень розглядалися можливості розгону дизель-поїзда за умови підтримки постійного (заданого) значення тягового моменту ТАД і за умови забезпечення мінімізації функціоналу (27) згідно синтезованих управлінь.

На рис. 1 - 4 приведені результати моделювання розробленої системи у вигляді перехідних процесів напруги живлення $U_{x 1}$, потокозчеплень $\Psi_{r m}$, управління $U_{1}$ та електромагнітного моменту ТАД $M_{d}$, що демонструють роботу моделі при певному значені управлінь $U_{1}$ і $U_{2}$ в системі керування і як реакції на управління об'єкта дослідження за умови підтримки постійного (заданого) значення тягового моменту ТАД і за умови забезпечення мінімізації функціоналу. Відповідно до синтезованих законів управління отримані показники витрат енергії (у вигляді споживчої потужності тяговим електроприводом та числових значень функціоналу) при розгоні дизель-поїзду при номінальній завантаженості в залежності від швидкості руху та пройденого шляху за певний проміжок часу. Як критерій оптимальності використовувався критерій мінімуму енергетичних витрат при виконанні обмежень по величині пройденого шляху i швидкості в кінцевий момент часу. Розглядалися варіанти впливу коефіцієнтів 
блоків моделей системи формування управлінь в процесі розгону дизель-поїзда за заданий час $\mathrm{t}$ i оцінювалися отримані характеристики (швидкість, пройдений шлях і енергетичні витрати). Результати дослідження приведені в табл. 1 і 2. На їх основі

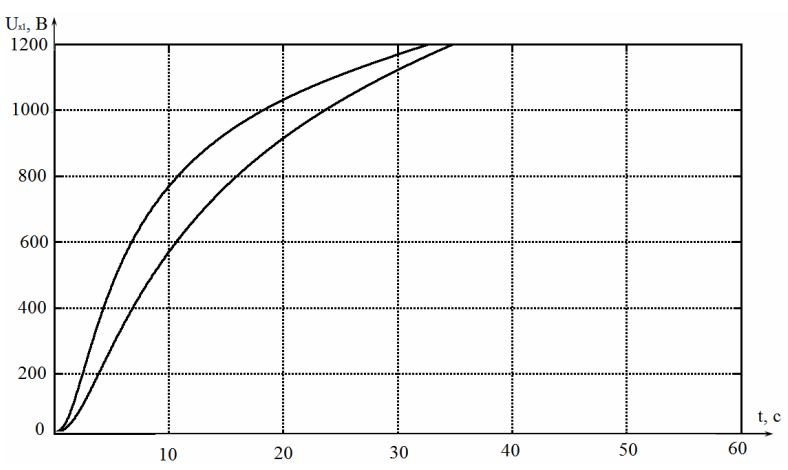

Рис. 1. Процеси зміни напруги живлення $U_{x 1}$ моделі ТАД в рухомій системі координат (нижній графік - при постійному моменті)

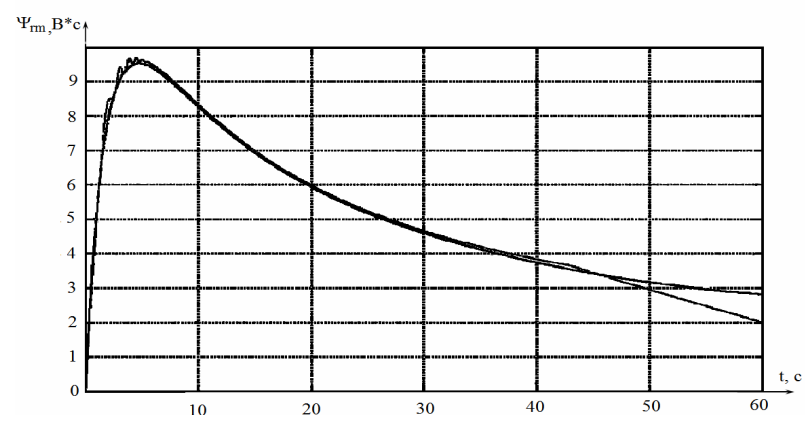

Рис. 2. Процеси зміни потокозчеплення $\Psi_{r m}$ (сформовані згідно закону управління і як вихідний сигнал моделі ТАД) уточнювались значення постійних інтегрування $C_{1} \mathrm{i}$ $C_{2}$ синтезованого закону управління $U_{1}$, які отримані шляхом рішення системи (44) у вигляді співвідношень (45) i (46), де $C_{21}, k_{3}$ - відповідно константа i коефіцієнт пропорціональності

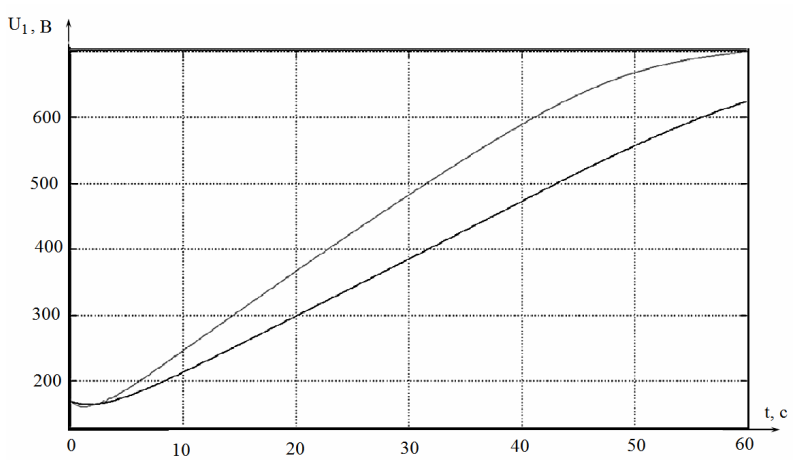

Рис. 3. Процеси зміни управління $U_{1}$ за умови підтримки постійного (заданого) значення тягового моменту ТАД і за умови забезпечення мінімізації функціоналу (верхній графік)

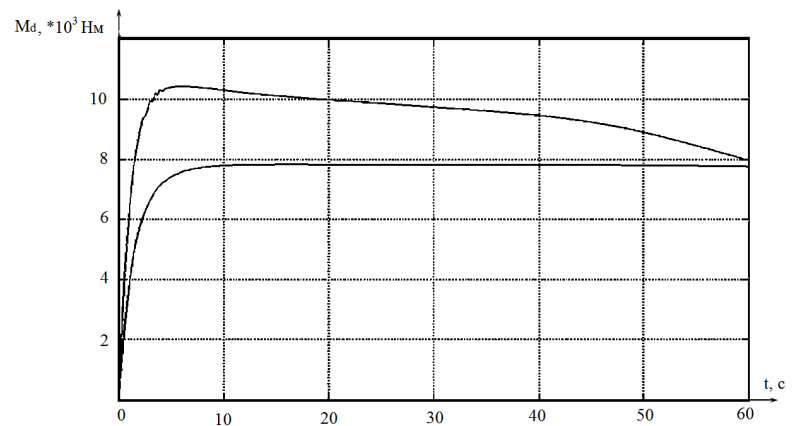

Рис. 4. Процеси зміни тягового моменту ТАД за умови підтримки постійного його значення і за умови забезпечення мінімізації функціоналу

Таблиия 1 - Результати досліджень

\begin{tabular}{|c|c|c|c|c|c|c|c|c|c|}
\hline$k_{3}=0.019$ & \multicolumn{4}{|c|}{$M_{d}=\mathrm{Const}=8000(\mathrm{HM})$} & \multicolumn{4}{|c|}{$M_{d}=\operatorname{Var}$} & \\
\hline$C_{21}$ & $\mathrm{~V}$, км/год & $\mathrm{S}, \mathrm{m}$ & $P^{*} 10^{6}$ & $J * 10^{6}$ & $\mathrm{~V}$, км/год & $\mathrm{S}, \mathrm{m}$ & $P^{*} 10^{6}$ & $J * 10^{6}$ & $\Delta P^{*} 10^{3}, 1 / \mathrm{M}$ \\
\hline 200 & 63.49 & 526.5 & 24.88 & 1.226 & 56.81 & 631.8 & 43.56 & 1.216 & 1.925 \\
\hline 180 & 62.45 & 516.3 & 22.04 & 0.973 & 63.42 & 667.9 & 38.19 & 1.111 & 1.663 \\
\hline 170 & 61.74 & 510.9 & 20.96 & 0.851 & 66.44 & 636.1 & 32.87 & 1.022 & 1.607 \\
\hline 160 & 60.98 & 504.7 & 20.18 & 0.730 & 65.78 & 578.9 & 25.16 & 0.895 & 1.546 \\
\hline 150 & 60.18 & 497.5 & 19.6 & 0.613 & 58.46 & 507.2 & 18.15 & 0.752 & 1.482 \\
\hline
\end{tabular}

Таблиия 2 -Результати досліджень

\begin{tabular}{|c|c|c|c|c|c|c|c|c|c|}
\hline$C_{21}=160$ & \multicolumn{4}{|c|}{$M_{d}=$ Const=8000 (Нм) } & \multicolumn{4}{c|}{$M_{d}=$ Var } & \\
\hline$k_{3}$ & $\mathrm{~V}$, км/год & $\mathrm{S}, \mathrm{м}$ & $P^{*} 10^{6}$ & $J^{*} 10^{6}$ & $\mathrm{~V}$, км/год & $\mathrm{S}, \mathrm{м}$ & $P^{*} 10^{6}$ & $J^{*} 10^{6}$ & $\Delta P^{*} 10^{3}, 1 / \mathrm{M}$ \\
\hline 0.013 & 56.67 & 469 & 17.39 & 0.35 & 42.85 & 402.9 & 9.76 & 0.49 & 1.216 \\
\hline 0.015 & 58.42 & 482.7 & 18.41 & 0.427 & 50.02 & 454.6 & 13.2 & 0.604 & 1.329 \\
\hline 0.017 & 59.77 & 494.3 & 19.26 & 0.567 & 58.57 & 514.9 & 18.15 & 0.739 & 1.435 \\
\hline 0.019 & 60.98 & 504.7 & 20.18 & 0.730 & 65.78 & 578.9 & 25.16 & 0.895 & 1.546 \\
\hline 0.021 & 62.13 & 513.19 & 21.48 & 0.90 & 65.89 & 628.5 & 32.9 & 1.04 & 1.654 \\
\hline
\end{tabular}

Як слідує із таблиць, як за умови використання закону управління формування тягового моменту ТАД за принципом $M_{d}=$ Const, так і за умови забезпечення мінімізації функціоналу синтезовані управління забезпечують формування частоти та напруги живлення ТАД в процесі розгону дизель-поїзда згідно заданих граничних умов (кінцевої швидкості та пройденого шляху).
Порівняння показників (показник $\Delta P$ ) виконувалось за відношенням абсолютного значення функціоналу до значення пройденого шляху за умови досягнення граничної межі заданої швидкості і пройденого шляху.

Для забезпечення виконання умов оптимізації в процесі досліджень встановлені межі допустимих значень коефіцієнтів синтезованих управлінь $C_{21}, k_{3}$ 
Межі допустимих значень: $C_{21}=(160 \div 180)$, $k_{3}=(0.017 \div 0.018)$. Оптимальними $€$ значення: $C_{21}=170, k_{3}=0.019$. При цьому різниця між сусідніми значеннями показників $C_{21}, k_{3}$ при визначені $\Delta P$ згідно таблиць не перевищує $0.3 \%$.

Виходячи 3 проведених результатів дослідження можна зробити висновок, що синтезовані управління та розроблена модель на основі використання алгоритму векторного управління електроприводом, дозволяють оптимізувати роботу енергетичної системи дизель-поїзда в процесі розгону при номінальному завантажені, забезпечуючи при цьому виконання заданих граничних умов, а також проводити дослідження аналогічних систем управління.

\section{Висновки}

1. Отримані аналітичні співвідношення можуть бути використані для розробки структури САР електроприводу дизель-поїзда і розрахунку іï параметрів при задані певного критерію якості при номінальному завантажені дизель-поїзда.

2. Запропонована методика розрахунку коефіцієнтів математичної моделі управлінь може бути адаптована при синтезі законів управління електроприводом змінного струму дизель-поїзда в залежності від конкретного завантаження в процесі розгону.

3. Оптимізаційна математична модель електроприводу змінного струму, закони управління, аналі- тичні співвідношення для визначення параметрів САР реалізовані у вигляді машинної моделі. Проведені дослідження показали перспективність такого підходу при розробці сучасних оптимальних систем управління електроприводом дизель-поїздів 3 тяговими двигунами змінного струму.

4. На підставі проведених досліджень і порівнянні результатів отриманих на моделі в динамічних режимах і за різних умов розгону дизель-поїзда (діапазону зміни коефіцієнтів моделі системи оптимальних управлінь) встановлено, що процес розгону при запропонованих законах управління стійкий, параметри системи електроприводу (напруги живлення та токи ТАД, потокозчеплення, величина ковзання) знаходяться в робочому діапазоні. При цьому виконуються вимоги щодо точності приведення об’єкта управління в задану точку фазового простору і якості управління.

5. Розроблена оптимізаційна модель на основі алгоритму векторного керування ТАД та запропоновані закони управління дозволяють оптимізувати роботу енергетичної системи дизель-потяга в процесі розгону, забезпечуючи при цьому виконання заданих граничних умов, а також проводити дослідження систем керування в замкнутій системі управління.

6. Синтезовані закони управління можуть бути покладені в основу системи керування в цілому при розробці автоматизованої системи управління рухом дизель-поїзда, де одним з основних принципів керування - підтримка заданої величини тягового моменту.

\section{СПИСОК ЛІТЕРАТУРИ}

1. Blaschke F. Das Prinzip der Feldorientierung. Die Grundlage für die Transvektor-Reglung von Drehfeldmaschine / F. Blaschke // Siemens Zaitschrift. - 1971. - № 45. - H. 10.

2. Усольцев А.А. Векторное управление асинхронными двигателями / А.А. Усольцев СПб: СПбГУ ИТМО, $2002 .-43$ с.

3. Сандлер А.С., Сарбатов Р.С. Автомат. частотное управление асинхронными двигателями. М.: Энергия, $1974 .-328$ с.

4. Рудаков В.В., Столяров, И.М., Дартау В.А. Асинхронные электроприводы с векторным управлением.- Л.: 1987.136 с.

5. Bose Bimal K. Modern Power Electronics and AC drives. Prentice Hall PTR: Prentice-Hall Inc. 2002. 712 p.

6. Моделирование и оптимизация систем управления и контроля локомотивов / [Носков В.И., Дмитриенко В.Д., Заполовский Н.И., Леонов С.Ю.]. - Х.: ХФИ «Транспорт Украины», 2003. - 248 с.

7. Volkov A.V., Kosenko I.A. Asynchronous motor drive based on self-excited current inverter with switched-off thyristors and provided with redicting relay and vector regulation of stator current. Published in Elektrotekhnika. 2008. No 10. P. 6-17.

8. Заполовський М.Й., Мезенцев М.В., Скородєлов В.В. Синтез управлінь для оптимізації динамічних процесів електроприводу змінного струму. Системи управління, навігації та зв язку. Вип. 4(50). Полтава. 2018. С. 38-41.

9. Заполовський М.Й. Математична модель для синтезу управлінь електроприводом змінного струму/ М.Й. Заполовський, В.В. Скородєлов, М.В. Мезенцев // Системи управління, навігації та зв'язку. - Вип. 5(57). Полтава. 2019. С. 16-21.

Received (Надійшла) 22.06.2020

Accepted for publication (Прийнята до друку) 26.08.2020

\section{Synthesis of diesel train controls with AC electric drive}

M. Zapolovsky, M. Mezentsev

Abstract. The task of synthesis of the control system of the traction electric drive of alternating current is an integral part of the general task of creation of optimum control system of vehicles that provides performance of the schedule according to the set quality criterion. The purpose of this work is to develop mathematical models for the synthesis of AC control system using vector control algorithm, synthesis of controls and research of their models, obtaining qualitative characteristics of the control system in the simulation process using MATLAB package. The issues of development and research of models for the synthesis of control systems for AC electric drive of an alternating current of a diesel train are considered. A review of literary sources on a given topic and an analysis of existing approaches to solving the most common problems in this area are carried out. Modern options using vector control algorithms are considered. Mathematical models are constructed, modeling of their functioning is carried out. The obtained analytical relations that can be used to develop the structure of the automatic control system of the electric drive of the diesel train and calculate its parameters when specifying a certain criterion taking into account a certain workload of the train. Control laws have been synthesized that provide stable acceleration of a diesel train at various points of the traction characteristic, while the requirements for the accuracy of bringing the control object to a given point in the phase space and the quality of transient processes are fulfilled.

Keywords: synthesis of control systems, AC electric drive, vector control algorithms, mathematical model, controls. 